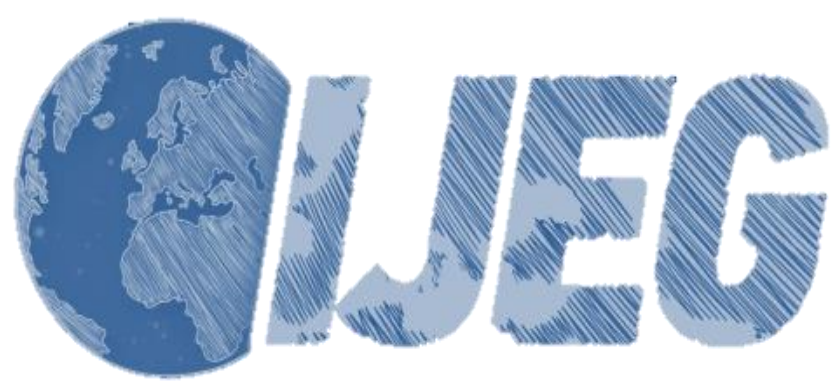

International Journal of Engineering and Geosciences (IJEG),

Vol; 5, Issue; 1, pp. 042-048, February, 2020, ISSN 2548-0960, Turkey,

DOI: $10.26833 /$ ijeg. 581568

\title{
THE GLOBAL AND LOCAL ROBUSTNESS ANALYSIS IN GEODETIC NETWORKS
}

\author{
Pakize Küreç Nehbit ${ }^{1 *}$, Haluk Konak ${ }^{2}$
}

${ }^{1}$ Kocaeli University, Faculty of Engineering, Department of Geomatic Engineering, Kocaeli, Turkey (pkurec80@yahoo.com); ORCID 0000-0003-2669-0401

${ }^{2}$ Kocaeli University, Institutes of Natural and Sciences, Department of Geodesy end Geoinformation, Kocaeli, Turkey (konak_haluk@yahoo.com); ORCID 0000-0003-2554-8905

*Corresponding Author, Received: 24/06/2019, Accepted: 20/07/2019

\begin{abstract}
The geodetic networks should be able to detect the possible earth crust movements caused by active tectonic movements in Turkey. Geodetic networks should also be able to determine the crust movements accurately as well as provide precision and reliability requests. The capacity of geodetic networks to determine the crustal movements can be determined by sensitivity analysis. Robustness analysis consists of strengthening internal reliability analysis with strain techniques. Robustness is defined as the deformation strength induced by the maximum undetectable errors with the internal reliability analysis. The robustness of a geodetic network is determined by the global initial condition, which aims at minimizing the total displacement value in the network. In this study, the local initial condition that aims to minimize the total displacement value at the uniform polyhedron, which consists of observations from each station points. The displacement values obtained according to the local and the global initial conditions are compared with threshold values. The results have also been interpreted.
\end{abstract}

Keywords: Sensitivity, Strain, Reliability, Geodetic Networks, Robustness. 


\section{INTRODUCTION}

Geodetic networks established for scientific or engineering purposes are expected to be robust enough to detect local deformations or tectonic movements of the region. For this reason, it is highly important that the sensitivity levels and the robustness are integrally queried when the quality of the geodetic networks is investigated. In geodetic networks, robustness is obtained from a function of reliability criteria. Even if the reliability criteria is sufficiently within the required limit values, in the geodetic networks, an outlier at an observation affects coordinate unknowns of each station point and leads to a different magnitude of deformation. Also, the station points are stretched in a different direction and ratio with the effect of an outlier at any observations. Therefore, investigation of the reliability of the geodetic networks can be considered as research of the external reliability vector which corresponds to the observation leading to the greatest strain at a station point (Vanicek et al., 1990; Berber, 2006; Konak, 2018). The external reliability vector depends on the number of datum points in free network solutions and distribution in the network. For this reason, the external reliability vector which causes the greatest strain can be defined as the vector having a maximum vector norm. In this case, the magnitude of the largest strain components is obtained independently of the datum using the strain models representing the surface formed by observation links of each station point. The estimated strain components for each station point are independent of the translation components of the strain area. However, while determining the displacement value of station points in the network, the effects of the translation components must also be eliminated. This process is accomplished with a global initial condition that aims to have a minimum total displacement magnitude. The corrected global displacement magnitudes are compared with the threshold value estimated from the confidence ellipsoids.

The robustness analysis has been first defined by Vanicek et al. (1990). In the study, an alternative geodetic network analysis to standard statistical analysis techniques has been developed to investigate the sensitivity of geodetic networks against outliers. The fundamental part of this alternative analysis, called Reliability Analysis, was introduced by Baarda (1976). This investigation process which was developed by a group of researchers at the University of New Brunswick was published as The Geometrical Strength Analysis. The differences between the reliability analysis and the benefits of the geometrical strength analysis are the subject of the study. Then, it was discovered that both of the analysis techniques are complementary to each other. The combined analysis method which consists of the reliability analysis and the geometrical strength analysis is called Robustness Analysis.

Basic deformation parameters are defined as relative translation, relative rotation, strain tensor and differential rotation components by Kuang (1991). Different strain models are explained according to the deformation model defined on the surface represented by any geodetic network with this study. The different mathematical models are proposed according to the homogeneous deformation of a whole surface and to the heterogeneous deformation explained with the movement of a surface relative to different centers of gravity by Kuang.

The displacement magnitude derived from the effects of the outliers on the coordinate unknowns is obtained independently according to the translation by Berber (2006). Therefore, it is aimed to determine a global initial condition for all station points of the network. These initial conditions are computed separately for 3D, 2D, and $1 \mathrm{D}$ geodetic networks. Displacement magnitudes are also obtained as 3D, 2D, and 1D.

In this study, local initial conditions aimed at minimizing the total displacement and developed for the polyhedron represented by each network point are proposed.

Global displacement magnitudes represent all station points of the network; however, local displacement magnitudes represent a surface formed by observation links of each neighbouring station point. The displacement vectors are comparable to the minimum undetectable displacement value (the sensitivity level) due to representing the effects of the undetectable outliers on the coordinate unknowns. For this reason, it is recommended that the local and the global displacement magnitudes computed for each station point should be compared with both the threshold values estimated from the confidence ellipsoid and the sensitivity levels suggested as a different threshold value (Küreç Nehbit, 2018).

\section{STRAIN IN GEODETIC NETWORKS}

Any tectonic plate or surface area can be identified as a kind of material or as a homogeneous object, despite its natural structures. When a force is applied to the surface, the resistance of the surface to this force can be determined mathematically and defined according to a coordinate system. The determination of the deformations on a surface in a coordinate system, independent from the datum and the geometric interpretation are explained by the concept of strain (Chou and Pagano, 1992; Konak, 2018; Küreç Nehbit, 2018).

Strain in the geodetic networks is defined as the ratio of the change in coordinate axies to the initial coordinate system. In other words, the strain is a geodetic/geometric interpretation of the deformation on a surface. Strains in the geodetic networks can be caused by the internal structure of the networks or by external factors. The strains arising from the internal structure of the network are affected by observation weights and observation plan. The strains due to external factors occur because of tectonic movements and local deformations (Küreç Nehbit, 2018).

Different mathematical methods are used to compute the strain components depending on the homogenous or heterogeneous deformation models defined on the surface. In the homogeneous deformation models, the deformation on a surface is equal in each region of the surface. On the other hand, in the heterogeneous deformation models, the deformations on a surface are different in every region of the surface. In this case, if the surface has a homogeneous deformation, the strain is described as a homogeneous strain. Also, if the surface has a heterogeneous deformation, the strain is identified as a heterogeneous strain (Vanicek et al., 1990; Kuang, 1991; Poyraz, 2009; Küreç Nehbit, 2018).

In geodetic networks measured at different times, the 
deformation vectors can be established according to the predicted deformation model for the displacement vector between two periods. The deformation model is selected according to a priori knowledge (Kuang, 1991; Küreç Nehbit, 2018).

At any station points, the displacement vector as a strain relationship can be written with the following equation;

$\Delta x_{i}=E_{i} x_{i}+c_{0}$

If the displacement vector is obtained in three dimensions, the strain matrix $\left(\mathrm{E}_{\mathrm{i}}\right)$ is identified as;

$E_{i}=\left[\begin{array}{lll}\frac{\partial u}{\partial x} & \frac{\partial u}{\partial y} & \frac{\partial u}{\partial z} \\ \frac{\partial v}{\partial x} & \frac{\partial v}{\partial y} & \frac{\partial v}{\partial z} \\ \frac{\partial w}{\partial x} & \frac{\partial w}{\partial y} & \frac{\partial w}{\partial z}\end{array}\right]=\left[\begin{array}{lll}e_{x x} & e_{x y} & e_{x z} \\ e_{y x} & e_{y y} & e_{y z} \\ e_{z x} & e_{z y} & e_{z z}\end{array}\right]$

(Vanicek et al., 1990; Vanicek et al., 2001; Konak, 2010; Küreç 2010; Küreç Nehbit, 2018).

\subsection{Surface Model Approach}

Strain components could be obtained from a function of coordinate differences or from velocity information. The mathematical models representing triangular or polygonal surfaces could be defined with Affine or the extended Helmert transformation (Konak et al., 2017; Küreç Nehbit, 2018; Öcalan, 2018).

The transformed coordinates according to the reference point are obtained as;

$\Delta x_{i}=X_{i}-X_{0}$

$\Delta y_{i}=Y_{i}-Y_{0}$

$\Delta z_{i}=Z_{i}-Z_{0}$

and using this transformed coordinates' differences, translation equations are written for each network point on a surface, where the strain components to be computed,

$v_{x_{k+1}}=x_{k+1}-x_{k}=t_{x}+\frac{\partial u}{\partial x} \Delta x_{i}+\frac{\partial u}{\partial y} \Delta y_{i}+\frac{\partial u}{\partial z} \Delta z_{i}$

$v_{y_{k+1}}=y_{k+1}-y_{k}=t_{y}+\frac{\partial v}{\partial x} \Delta x_{i}+\frac{\partial v}{\partial y} \Delta y_{i}+\frac{\partial v}{\partial z} \Delta z_{i}$

$v_{z_{k+1}}=z_{k+1}-z_{k}=t_{z}+\frac{\partial w}{\partial x} \Delta x_{i}+\frac{\partial w}{\partial y} \Delta y_{i}+\frac{\partial w}{\partial z} \Delta z_{i}$

$d_{i}=H_{i} \cdot g$

where $(k)$ is epoch number, $\left(P_{0}\right)$ is reference points, $\left(d_{i}\right)$ is displacement vector, $\left(\mathrm{H}_{\mathrm{i}}\right)$ is the design matrix, $(\mathrm{g})$ is the vector of the strain components. 3D affine transformation matrix representing homogeneous strain properties is defined as;

$H_{i}=\left[\begin{array}{cccccccccccc}1 & 0 & 0 & \Delta x_{i} & \Delta y_{i} & \Delta z_{i} & 0 & 0 & 0 & 0 & 0 & 0 \\ 0 & 1 & 0 & 0 & 0 & 0 & \Delta x_{i} & \Delta y_{i} & \Delta z_{i} & 0 & 0 & 0 \\ 0 & 0 & 1 & 0 & 0 & 0 & 0 & 0 & 0 & \Delta x_{i} & \Delta y_{i} & \Delta z_{i}\end{array}\right](6)$

and the displacement vector is obtained as;

$d_{i}^{T}=\left[\begin{array}{lll}v_{x} & v_{y} & v_{z}\end{array}\right]$

In this way, Affine Model is formulated (Kuang, 1991). In this case, strain components with $3 \mathrm{D}$ are determined with the following equations;
$g=\left(H^{T} H\right)^{-1} H^{T} d$

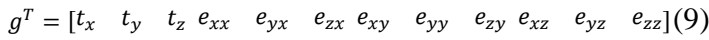

\section{ROBUSTNESS ANALYSES FOR THE GEODETIC NETWORKS}

Robustness is defined as the deformation strength caused by the undetectable possible model error with the internal reliability analyses. Robustness analyses consist of strengthening internal reliability analyses with strain techniques. In any observation, the effect of outliers on the coordinate unknowns is obtained as;

$\Delta X=Q A^{T} P \Delta_{0 i}$

$\delta_{0 i}^{2}=\Delta X^{T} K_{x x}^{-1} \Delta X$

and is determined for experimental observation as

$\delta_{0 i}^{2}=m_{0}^{2} \frac{\delta_{0}}{e_{i}^{T} P Q_{v v} P e_{i}}$

This squared magnitude called external reliability is a criterion independent from the selection of datum points in free networks. On the other hand, the effect of the outliers, which are interpreted as the displacement vector, on the coordinate unknowns are identified with the following equations;

$\Delta X^{T}=\left[\Delta X_{1} ; \quad \Delta X_{2} ; \quad \ldots \quad \ldots \quad \ldots ; \quad \Delta X_{u}\right]$

$\Delta X_{i}=\left[\begin{array}{c}\Delta x_{i} \\ \Delta y_{i} \\ \Delta z_{i}\end{array}\right]=\left[\begin{array}{c}u_{i} \\ v_{i} \\ w_{i}\end{array}\right]$

The vector magnitude, which can be computed as much as the number of observations for any coordinate unknown, is stretched in different magnitude and directions depending on the observation weights. In this case, this vector magnitude $\left(\Delta \mathbf{X}_{\mathbf{0} \mathbf{i}}\right)$;

$\Delta X_{0 i}=\max \left\{\left|\Delta X_{i}\right|\right\}$

causing the greatest strain must be queried. The observation that causes the greatest strain is assumed to be the observation with the largest vector norm. To determine the largest vector norm, either L1 norm, Euclidean (L2) norm or Weighted Euclidean norms could be used. The most appropriate vector norm that could be compared with the external reliability criterion is the Euclidean (L2) norm.

$\|\Delta x\|=\sqrt{\left(\Delta X_{1}\right)^{2}+\left(\Delta X_{2}\right)^{2}+\cdots \ldots \ldots+\left(\Delta X_{u}\right)^{2}}$

When determining the largest vector norms; if there is any equality between the Euclidean norms of the observations, the observation which has the largest external reliability value should be chosen $\left(\delta_{0 \mathrm{i}}\right.$; Weighted Euclidean norms).

The strain resulting from the effect of undetectable errors on the coordinate unknowns is obtained using the Affine or the extended Helmert transformation model for the surface representing each station point. 
The strains are independent of the location of the surface (initial conditions, $\mathrm{X}_{0}, \mathrm{Y}_{0}, \mathrm{Z}_{0}$ ) in a coordinate system. In this case, the strain tensor matrix $\mathrm{E}_{\mathrm{i}}$ with respect to a selected reference point $\mathrm{P}_{0}$ on the surface is obtained by the following equation;

$\left[\begin{array}{c}\Delta x_{i} \\ \Delta y_{i} \\ \Delta z_{i}\end{array}\right]=\left[\begin{array}{lll}e_{x x} & e_{x y} & e_{x z} \\ e_{y x} & e_{y y} & e_{y z} \\ e_{z x} & e_{z y} & e_{z z}\end{array}\right]\left[\begin{array}{c}X_{i}-X_{0} \\ Y_{i}-Y_{0} \\ Z_{i}-Z_{0}\end{array}\right]$

\subsection{Determination of Deformation Vectors}

Robustness analysis procedures are based on determining the magnitude of the deformation vector leading to strain at any station point and investigating the significance level. In this case, an initial condition $\left(\mathrm{P}_{0}\right)$ representing the network is required in order to calculate a deformation vector at each point according to equation (17). This value is the estimation value that "makes minimum squares of corrections brought to the center of gravity coordinates of the polyhedron representing each point" (Berber, 2006; Küreç Nehbit, 2018).

To determine the initial conditions/translation parameters, the norm of the displacement vector elements at all network points is intended to be minimum. The objective function is arranged as following;

$\min \left\{\sum_{i=1}^{n}\|\Delta \vec{r}\|_{i}\right\}=\min \left\{\sum_{i=1}^{n}\left(u_{i}^{2}+v_{i}^{2}+w_{i}^{2}\right)\right\}$

where (n) is the number of station points in the network. The objective function is linearized separately according to the initial conditions $\left(\mathrm{X}_{0}, \mathrm{Y}_{0}, \mathrm{Z}_{0}\right)$. Linearization of the objective function according to $\left(\mathrm{X}_{0}\right)$;

$$
\begin{aligned}
& \sum_{i=1}^{n}\left[\begin{array}{c}
\left.\left(-\frac{\partial u_{i}}{\partial x} \frac{\partial u_{i}}{\partial x}-\frac{\partial v_{i}}{\partial x} \frac{\partial v_{i}}{\partial x}-\frac{\partial w_{i}}{\partial x} \frac{\partial w_{i}}{\partial x}\right) X_{0}+\left(-\frac{\partial u_{i}}{\partial y} \frac{\partial u_{i}}{\partial x}-\frac{\partial u_{i}}{\partial x}-\frac{\partial v_{i}}{\partial y} \frac{\partial v_{i}}{\partial x}-\frac{\partial v_{i}}{\partial x}-\frac{\partial w_{i}}{\partial y} \frac{\partial w_{i}}{\partial z}\right) Y_{0}+\frac{\partial w_{i}}{\partial x}\right) Z_{0}+\left(\frac{\partial u_{i}}{\partial x} \frac{\partial u_{i}}{\partial x}+\frac{\partial v_{i}}{\partial} \frac{\partial v_{i}}{\partial x}+\frac{\partial w_{i}}{\partial x} \frac{\partial w_{i}}{\partial x}\right) X_{i}+ \\
\left(\frac{\partial u_{i}}{\partial y} \frac{\partial u_{i}}{\partial x}+\frac{\partial v_{i}}{\partial y} \frac{\partial v_{i}}{\partial x}+\frac{\partial w_{i}}{\partial y} \frac{\partial w_{i}}{\partial x}\right) Y_{i}+\left(\frac{\partial u_{i}}{\partial z} \frac{\partial u_{i}}{\partial x}+\frac{\partial v_{i}}{\partial z} \frac{\partial v_{i}}{\partial x}+\frac{\partial w_{i}}{\partial z} \frac{\partial w_{i}}{\partial x}\right) Z_{i}
\end{array}\right] \\
& \frac{\partial \sum_{i=1}^{n}\|\Delta \vec{r}\|_{i}}{\partial X_{0}}=\sum_{i=1}^{n}\left[a_{1} X_{0}+b_{1} Y_{0}+c_{1} Z_{0}+d_{1}\right]=0
\end{aligned}
$$

linearization of the objective function according to $\left(\mathrm{Y}_{0}\right)$;

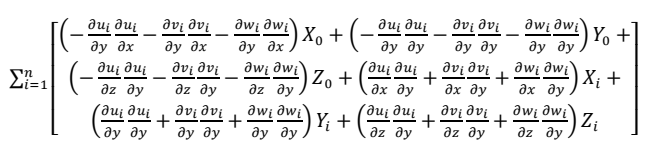

$\frac{\partial \sum_{i=1}^{n}\|\Delta \vec{r}\|_{i}}{\partial Y_{0}}=\sum_{i=1}^{n}\left[a_{2} X_{0}+b_{2} Y_{0}+c_{2} Z_{0}+d_{2}\right]=0$

and linearization of the objective function according to $\left(\mathrm{Z}_{0}\right)$;

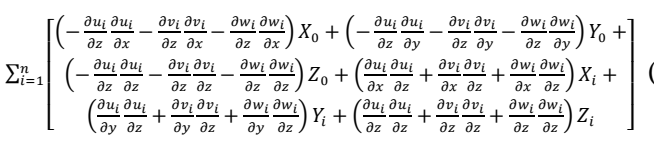

$\frac{\partial \sum_{i=1}^{n}\|\Delta \vec{r}\|_{i}}{\partial Z_{0}}=\sum_{i=1}^{n}\left[a_{3} X_{0}+b_{3} Y_{0}+c_{3} Z_{0}+d_{3}\right]=0$

The objective function given by equation (18) is arranged with the following equation;

$\sum_{i=1}^{n}\left(\Delta r^{T} \Delta r\right)_{i}=\sum_{i=1}^{n}\left(X_{i}-X_{0}\right)^{T} E_{i}^{T} E_{i}\left(X_{i}-X_{0}\right) \Rightarrow \min$

(22)
The objective function is rewritten as;

$\sum_{i=1}^{n}\left(\Delta r^{T} \Delta r\right)_{i}=\sum_{i=1}^{n}(\Delta x)^{T} E_{i}^{T} E_{i}(\Delta x) \Rightarrow \min$

Also, it is linearized according to the initial conditions. In this case, normal equations are obtained by linearizing;

$$
\begin{aligned}
& d\left\{\sum_{i=1}^{n}\left(\Delta r^{T} \Delta r\right)_{i}\right\}=0 \\
& -\sum_{i=1}^{n} E_{i}^{T} E_{i} X_{0}+\sum_{i=1}^{n} E_{i}^{T} E_{i} X_{i}=0
\end{aligned}
$$

The initial conditions $\boldsymbol{X}_{\mathbf{0}}^{T}=\left[\boldsymbol{X}_{\mathbf{0}}, \boldsymbol{Y}_{\mathbf{0}}, \boldsymbol{Z}_{\mathbf{0}}\right]$ are computed with the following equation;

$X_{0}=\left[\sum_{i=1}^{n} E_{i}^{T} E_{i}\right]^{-1} \sum_{i=1}^{n} E_{i}^{T} E_{i} X_{i}$

(Berber, 2006; Konak, 2018; Küreç Nehbit, 2018). The solution vector in Eq. (26) could be shown as follows;

$\left[\begin{array}{l}X_{0} \\ Y_{0} \\ Z_{0}\end{array}\right]=\left[\begin{array}{lll}{\left[a_{1}\right]} & {\left[b_{1}\right]} & {\left[c_{1}\right]} \\ {\left[a_{2}\right]} & {\left[b_{2}\right]} & {\left[c_{2}\right]} \\ {\left[a_{3}\right]} & {\left[b_{3}\right]} & {\left[c_{3}\right]}\end{array}\right]^{-1}\left[\begin{array}{l}{\left[d_{1}\right]} \\ {\left[d_{2}\right]} \\ {\left[d_{3}\right]}\end{array}\right]$

If the obtained initial conditions are written in the equation (17), the corrected global displacement vector is obtained.

Translation value of the global displacement vector (corrected global displacement vector) relative to the gravity center is obtained as;

$d_{G i}=\sqrt{u_{G i}^{2}+v_{G i}^{2}+w_{G i}^{2}}$

The corrected global displacement vector could also be estimated from the surface represented by each station point instead of the whole network. In this context, local initial conditions can be estimated which aim at minimizing the total displacement for the polyhedron represented by each network station point, with a new approach developed. The strains computed for each station point represent the surface which consists of observations of each station point. In this case, corrected local initial conditions are determined for each surface area with the following equations;

$-m\left(E^{T} E\right)_{i} X_{L 0}+m\left(E^{T} E\right)_{i} X_{i}=0$

$X_{L 0}=\left(E^{T} E\right)_{i}^{-1} E_{i}^{T} E_{i} \sum_{i=1}^{m} X_{i}$

where $(\mathrm{m})$ is station points number on surface. Using the computed local initial conditions;

$\left[\begin{array}{c}u \\ v \\ W\end{array}\right]_{L i}=E_{i}\left[\begin{array}{l}X-X_{L 0} \\ Y-Y_{L 0} \\ Z-Z_{L 0}\end{array}\right]_{i}$

the local displacement vector magnitude $\left(d_{L i}\right)$ is computed as;

$d_{L i}=\sqrt{u_{L i}^{2}+v_{L i}^{2}+w_{L i}^{2}}$

The displacement magnitudes obtained as the local and 
the global are compared with the threshold value $\left(\delta_{i}\right)$ estimated from the confidence ellipsoid;

$\delta_{i}=m_{0} \sqrt{3 \cdot F_{h, f, 1-\alpha} \cdot i z\left(Q_{x x}\right)}$

In the case of $d_{G i}>\delta_{i}$ and of $d_{L i}>\delta_{i}$, it can be said that the network station point discussed is not robust (not sufficiently reliable) in respect of the global and the local (Berber, 2006; Küreç Nehbit, 2018).

It is expected that a network is insensitive to possible outliers and the disruptive effect of the outliers (strains, deformation vectors) on the coordinate unknowns are as low as possible. On the other hand, the networks should be able to detect the negative influence of these effects on the displacement vector sufficiently. In other words, the more robust a network is, the more sensitive it is to outliers in observations or changes over time.

Therefore, the sensitivity and robustness distributions should be evaluated and interpreted together. Because of the displacement vectors obtained at any station point in the network represent the external reliability values, these are also comparable with the sensitivity values.

In this case, the inequation of non-centrality distribution is recommended as a threshold value instead of the equation (34) for the displacement vectors at each network point;

$\frac{d^{T} Q_{d d}^{-1} d}{\sigma^{2}} \leq \delta_{0}^{2}$

where $\mathrm{d}$ is the displacement vector, $Q_{d d}$ is cofactor matrix of the displacement vector, $\delta_{0}$ is the threshold value of the non-centrality parameter, $\sigma^{2}$ is a priori variance of the average error of the unit observation. In equation (34), the quadratic value of the displacement vector $\left(d^{T} Q_{d d}^{-1} d\right)$ is rearranged according to the eigenvalue and eigenvector separation and orthogonality conditions, and the sensitivity value of each station point is obtained;

$\|d\|_{\min }=\frac{\delta_{0} \sigma}{\sqrt{\lambda_{\max }}}$

(Hsu and Hsiao, 2002; Küreç, 2010; Küreç and Konak, 2011 and 2014; Küreç Nehbit, 2018; Kirici Yildirim and Sisman, 2019).

\section{NUMERICAL APPLICATION}

In this study, the data of IZDOGAP Densification Global Positioning System (GPS) Network established for the Monitoring of IZGAZ Natural Gas Infrastructure with Geodetic Networks and Information System Project (IZDOGAP) is used. Observation plan of the densificated IZDOGAP GPS network has been obtained using the second order weight optimization (Figure 1). The network measured in 2009 and 2010 has been evaluated with obtained GPS observations respectively. Also, the robustness level of the IZDOGAP network has been queried.

Robustness investigations are performed using displacement vectors resulting from the effect of the outliers on the coordinate unknowns. In this investigation process, the displacement magnitude can be obtained as much as the number of observations at each station point.
Determining the deformation resistance or strain caused by the observation having the greatest effect on the coordinate unknowns is very important in terms of robustness analysis. Therefore, the observation with the greatest effect on coordinate unknowns should be estimated independently from the datum. Various vector norms have been tested for the estimation processes and it has been decided to use Euclidean norm (L2 norm) which gives an unbiased result. Strain components are computed for Densificated IZDOGAP GPS Network by using displacement vector having the greatest effect on coordinate unknowns determined according to Euclidean norm.

Strain components are obtained in 3D using the adjusted Affine transformation process for the surface representing each station points. The deformation vectors resulting from the strain are estimated for each station point with the obtained strain information. Initial conditions are required for deformation vectors to be estimated as independent of translation and consistent. In this study, initial conditions are obtained by two different approaches: local and global. The corrected displacement vectors for each station point are estimated separately using the local and global initial conditions. In other words, the robustness level of each station point is determined both locally and globally. The deformation values obtained have been compared with the threshold value computed using equation (33) and the significance of the deformation vector is tested.

The displacement vectors obtained for any station point represent the effect of undetectable errors on coordinate unknowns. Therefore, the displacement vector can be interpreted as a value comparable to the sensitivity level $\left(\mathrm{d}_{\mathrm{min}}\right)$. For this reason, computed local and global deformation vectors are compared with the sensitivity levels of each station point $\left(\mathrm{d}_{\min }\right)$ obtained with equation (35) (Table 1).

\section{CONCLUSION}

When the corrected displacement magnitudes computed using the 2009 and 2010 epoch observations of densified IZDOGAP GPS Network for all network points are examined, it is seen that;

- The magnitude of the displacement vector estimated according to the local approach is generally smaller than estimated values according to the global approach.

- On the other hand, in epoch 2009.370, local displacement vectors at station points 103 and 38 are higher than global displacement vectors. If the locations of these station points are examined in Figure 1, it is observed that they are located in external zone points. In the 2010.496 epoch, the magnitudes of local deformation vectors at station points 73 and 42 are higher than global deformation vectors.

- In the epochs, 2009.370 and 2010.496, the local and global displacement vectors obtained for each station point do not exceed threshold value obtained from the confidence ellipse components.

- As a result, the IZDOGAP GPS Network is robust at all points and the sensitivity values are reliable. 
International Journal of Engineering and Geosciences (IJEG), Vol; 5, Issue; 1, pp. 042-048, February, 2020,

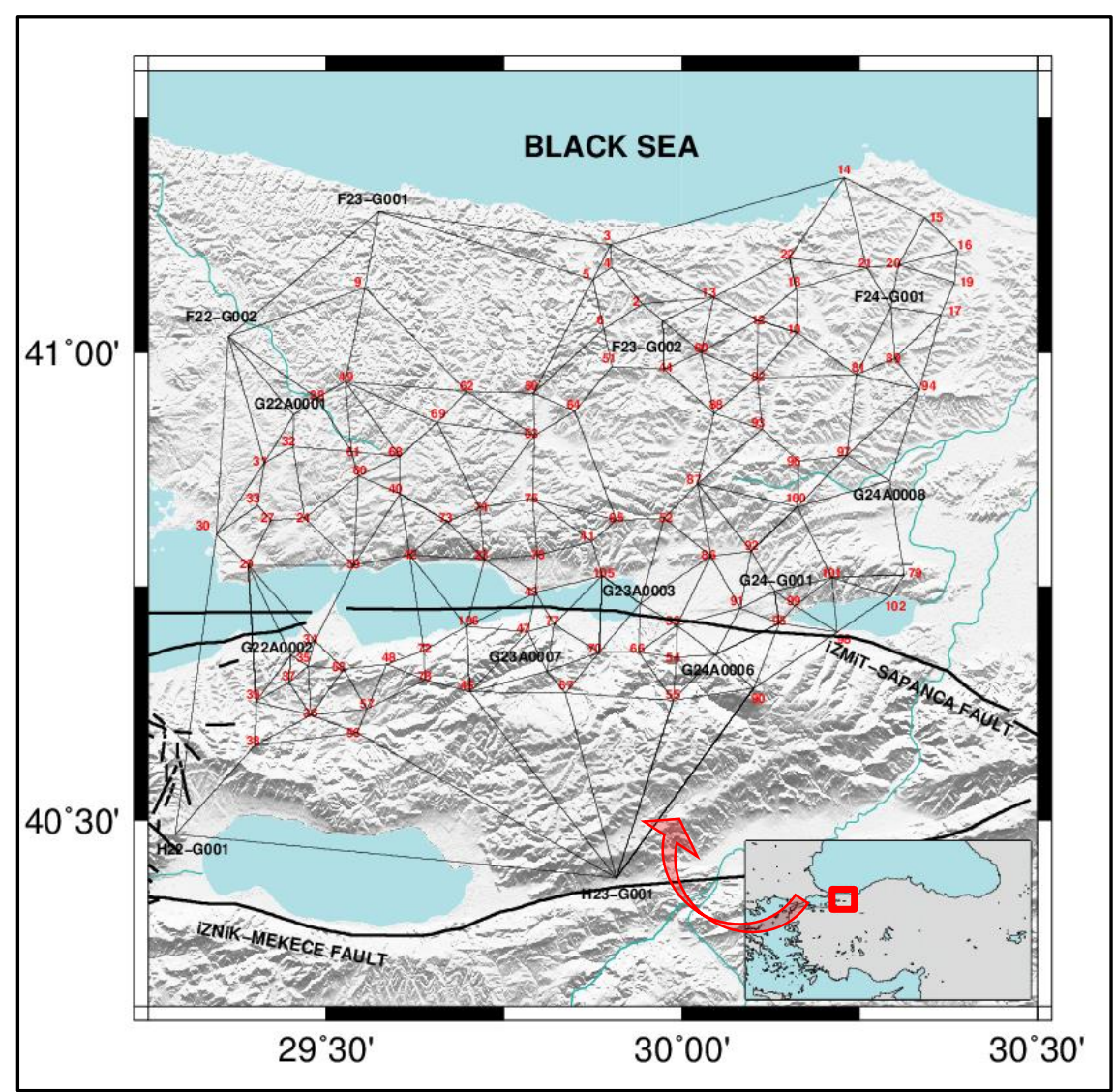

Figure 1. The densified Kocaeli IZDOGAP GPS network

Table 1. A Priori Robustness Synthesis $(\mathrm{cm})$

\begin{tabular}{|c|c|c|c|c|c|c|c|c|}
\hline & \multicolumn{4}{|c|}{ Epoch 2009.370 } & \multicolumn{3}{c|}{ Epoch 2010.496 } \\
\hline \multirow{2}{*}{$\begin{array}{c}\text { P. } \\
\text { Num. }\end{array}$} & Deformation Vec. & \multicolumn{2}{|c|}{ Thresholds } & Deformation Vec. & \multicolumn{2}{|c|}{ Thresholds } \\
\cline { 2 - 10 } & Local & Global & $\boldsymbol{\delta}_{\boldsymbol{i}}$ & $\begin{array}{c}\mathrm{d}_{\min } \\
\left(\mathrm{m}_{0}\right)\end{array}$ & Local & Global & $\boldsymbol{\delta}_{\boldsymbol{i}}$ & $\begin{array}{c}\mathrm{d}_{\min } \\
\left(\mathrm{m}_{0}\right)\end{array}$ \\
\hline 3 & 0.0006 & 0.0133 & 3.12 & 1.15 & 0.0028 & 0.0216 & 5.55 & 1.97 \\
\hline 10 & 0.0005 & 0.0187 & 2.98 & 1.07 & 0.0018 & 0.0380 & 5.69 & 2.06 \\
\hline 14 & 0.0015 & 0.1059 & 4.17 & 1.57 & 0.0052 & 0.2707 & 8.34 & 2.61 \\
\hline 15 & 0.0001 & 0.0070 & 4.12 & 1.54 & 0.0014 & 0.0355 & 7.66 & 2.61 \\
\hline 16 & 0.0002 & 0.0122 & 4.04 & 1.47 & 0.0003 & 0.0238 & 7.22 & 2.47 \\
\hline 19 & 0.0001 & 0.0103 & 3.69 & 1.37 & 0.0003 & 0.0185 & 7.03 & 2.42 \\
\hline 20 & 0.0001 & 0.0255 & 3.49 & 1.29 & 0.0001 & 0.0386 & 6.58 & 2.26 \\
\hline 21 & 0.0004 & 0.0131 & 3.32 & 1.20 & 0.0015 & 0.0134 & 6.48 & 2.24 \\
\hline 30 & 1.0206 & 0.0530 & 3.61 & 1.18 & 0.0122 & 0.0485 & 7.67 & 2.73 \\
\hline 33 & 0.0192 & 0.2043 & 3.23 & 1.18 & 0.0041 & 0.1323 & 7.96 & 2.71 \\
\hline 38 & 1.5879 & 0.0939 & 3.63 & 1.36 & 0.0097 & 0.0592 & 13.94 & 4.16 \\
\hline 56 & 0.0362 & 0.3403 & 4.16 & 1.05 & 0.0089 & 0.1552 & 8.48 & 2.90 \\
\hline 64 & 0.0013 & 0.0818 & 2.69 & 0.95 & 0.0330 & 0.2971 & 4.96 & 1.67 \\
\hline 73 & 0.0021 & 0.0838 & 2.34 & 0.80 & 7.6174 & 0.8845 & 13.09 & 3.55 \\
\hline 74 & 0.0025 & 0.0343 & 2.36 & 0.79 & 2.0290 & 2.4175 & 6.66 & 2.24 \\
\hline 79 & 0.0023 & 0.0411 & 3.95 & 1.39 & 0.0081 & 0.0454 & 8.51 & 3.29 \\
\hline 98 & 0.0048 & 0.0130 & 3.37 & 1.19 & 0.0020 & 0.0354 & 6.30 & 2.33 \\
\hline 99 & 0.0002 & 0.0238 & 2.97 & 1.04 & 0.0011 & 0.0577 & 6.12 & 2.21 \\
\hline 101 & 0.0010 & 0.0100 & 3.18 & 1.10 & 0.0034 & 0.0174 & 6.30 & 2.34 \\
\hline 103 & 5.4968 & 0.2282 & 6.49 & 2.31 & 0.0143 & 0.0452 & 14.46 & 4.44 \\
\hline
\end{tabular}


External reliability vectors consist of a plurality of sub-vector components close to and equal to zero according to the observation plan of the network. On the other hand, a global displacement vector is estimated for the robustness analysis. As a result, the magnitude of the local and global displacement vector changes according to the selection of initial conditions. In other words, the local displacement vector at a point represents a common surface consisting of neighboring station points. Therefore, it is very sensitive to the weights of the observations and the location in the observation plan. In this case, the local displacement vector recommended as a local comparison criterion can be used as a local query detector.

- When the local displacement vectors have been examined in the 2009.370 epoch, it is observed that displacement vector values $\left(\mathrm{d}_{\min }\right)$ at station points 103 and 38 exceed the limit value. In the 2009.370 epoch, the external reliability value of the 103-38 base observation disrupts the reliability distribution. However, in both 2009.370 and 2010.496 epochs, sensitivity values of stations 103 and 38 are obtained at a high level (Figure 1, Table 1).

- In the 2010.496 epoch, at station points of 74 and 201 (23), global displacement vectors have exceeded the $\left(d_{\min }\right)$ threshold value. At station points 73 and 42, only local displacement vectors have exceeded the $\left(d_{\min }\right)$ threshold value. At these points, the sensitivity values are also relatively weak (Table 1 ).

When the findings have been analyzed, it is observed that the global displacement magnitudes have more optimistic results. On the other hand, the local displacement vector at a point represents the common surface formed by neighboring points. Therefore, it is very sensitive to the observation weights and its locations in the network. As a result of this feature, the local displacement vectors can detect the possible outliers on the surface.

As a result; in this study, the displacement vector used as a local comparison criterion is suggested to be used as a local query detector.

\section{REFERENCES}

Berber M., (2006), Robustness analysis of geodetic networks, Ph.D. Thesis, University of Brunswick, Canada.

Hsu R., Hsiao K., (2002), Pre-computing the sensitivity of a GPS station for crustal deformation monitoring, Journal of the Chinese Institute of Engineers, 25(6), 715722 .

Kirici Yildirim, U., Sisman, Y., (2019), The deformation Analysis using hypothesis tests, International Journal of Engineering and Geosciences (IJEG), 4(2), 88-93.

Konak H., (2010), Jeodezik ağlar ve uygulamaları ders notları, KOÜ Mühendislik Fakültesi, Kocaeli.
Konak H., Küreç Nehbit P., İnce C. D., (2017), Yaşamsal altyap1 sistemlerinin GPS ağlarıyla izlenmesi ve deformasyon sonuçlarının yorumlanmasi: Kocaeli İZDOGAP GPS ağı uygulaması, Geomatik Dergisi, 2(1), 40-52.

Konak H., (2018), Jeodezik ağlarda sağlamlık ders notları, KOÜ, FBE, Joedezi ve Jeoinformasyon Mühendisliği Anabilim Dalı.

Kuang, S., (1991), Optimization and design of deformation monitoring schemes, Ph.D. Dissertation, Department of Surveying Engineering Technical Report, University of New Brunswick, 157, 1991.

Küreç P., (2010), Yüzey ağlarının değerlendirilmesi, Yüksek Lisans Tezi, KOÜ Fen Bilimleri Enstitüsü, Kocaeli.

Küreç P., Konak H., (2011), Sıklaştırma ağlarının yer kabuğu hareketlerine karşı duyarlıkları ve olası algilayabilirlik düzeyleri, hkm Jeodezi, Jeoinformasyon ve Arazi Yönetimi Dergisi, Özel Sayı, 84-90.

Küreç P., Konak H., (2014), A priori sensitivity analysis for densification GPS networks and their capacities of crustal deformation monitoring: a real GPS network application, Nat. Hazards Earth Syst. Sci., 14, 1299-1308.

Küreç Nehbit P., (2018), GPS/GNSS ağları için sürekli bir gerinim izleme ve kalite değerlendirme stratejisi, Doktora Tezi, KOÜ Fen Bilimleri Enstitüsü, Kocaeli.

Öcalan, T., (2018), Investihation on the effects of number of common points in 2D transformation problem, International Journal of Engineering and Geosciences (IJEG), 4(2), 58-62.

Poyraz F., (2009), Kuzey Anadolu fay zonu doğu kesiminde yatay yerkabuğu hareketleri ve gerilme birikiminin araştırılması, Doktora Tezi, Yıldız Teknik Üniversitesi, Fen Bilimleri Enstitüsü, Istanbul.

Vanicek P., Craymer M. R., Krakiwsky E. J., (2001), Robustness Analysis of Geodetic Horizontal Networks, Journal of Geodesy, 75(4), 199-209.

Vanicek P., Krakiwsky E. J., Craymer M. R., Gao Y., Ong P. S., (1990), Robustness Analysis, Final contract report, Department of Surveying Engineering Technical Report, University of New Brunswick, 156.

Chou P.C., Pagano, N.J., (1992), Elasticity Elasticity. Tensor, Dyadic and Engineering Approaches, ISBN 0486669580. 